九州大学学術情報リポジトリ

Kyushu University Institutional Repository

\title{
Photophysical characteristics of 4,4 ' -bis(N- carbazolyl)tolan derivatives and their application in organic light emitting diodes
}

Ohkita, Masakazu

Graduate School of Materials Science and Engineering, Nagoya Institute of Technology

Endo, Ayataka

Center for Future Chemistry, and Center for Organic Photonics and Electronics Research (OPERA), Kyushu University

Sumiya, Kimihiro

Graduate School of Materials Science and Engineering, Nagoya Institute of Technology

Nakanotani, Haj ime

Center for Future Chemistry, and Center for Organic Photonics and Electronics Research (OPERA), Kyushu University

他

http://hdl. handle. net/2324/25674

出版情報：Journal of Luminescence. 131 (7)，pp.1520-1524，2011-07. Elsevier バージョン：

権利関係: (C) 2011 Elsevier B.V. 


\section{Photophysical characteristics of 4,4 '-bis( $N$-carbazolyl)tolan derivatives and their}

application in organic light emitting diodes

Masakazu Ohkita ${ }^{\mathrm{a}}$, Ayataka Endo ${ }^{\mathrm{b}}$, Kimihiro Sumiya $^{\mathrm{a}}$, Hajime Nakanotani ${ }^{\mathrm{b}}$, Takanori Suzuki ${ }^{\mathrm{c}}$, and Chihaya Adachi ${ }^{\mathrm{b}, *}$

${ }^{a}$ Graduate School of Materials Science and Engineering, Nagoya Institute of Technology, Nagoya 466-8555, Japan

${ }^{\mathrm{b}}$ Center for Future Chemistry, and Center for Organic Photonics and Electronics Research (OPERA), Kyushu University, Fukuoka 819-0395, Japan

${ }^{\mathrm{c}}$ Division of Chemistry, Graduate School of Science, Hokkaido University, Sapporo 060-0810, Japan

* Corresponding author. Tel. : +81-92-802-3306; fax : +81-92-802-3306.

E-mail address: adachi@cstf.kyushu-u.ac.jp

Abstract: $\quad 4,4^{\prime}$-Bis( $N$-carbazolyl)tolan $\quad$ (BCT) and $4,4^{\prime}$-bis[ $N$-(3,6-di-t-butyl)carbazolyl]tolan (BCT-t-Bu) were synthesized as $\pi$-expanded analogues of $4,4^{\prime}$-bis( $N$-carbazolyl)biphenyl. Their photophysical characteristics both in solution and films were thoroughly investigated. Interestingly, 
the phosphorescence spectrum of BCT was significantly medium dependent, and the emission maximum was red-shifted by $131 \mathrm{~nm}$ from $489 \mathrm{~nm}$ in solution at $77 \mathrm{~K}$ to $620 \mathrm{~nm}$ in a deposited film at $5 \mathrm{~K}$, suggesting the presence of strong intermolecular interactions in the film. BCT and BCT-t-Bu were found to be useful as host materials for fluorescence-based organic light emitting diodes (OLEDs). However, their low triplet energy levels in films negated their potential to act as hosts in phosphorescence-based OLEDs.

Keywords: Carbazole; Acetylene; Photophysical properties; Organic light emitting diodes; Host materials.

\section{Introduction}

Carbazole-based $\pi$-electron systems have attracted considerable attention in materials science because of their unique light emitting [1,2], carrier transporting [3,4] and photorefractive [5,6] properties, which may find application in organic electronic and optoelectronic devices. 4,4'-Bis( $N$-carbazolyl)biphenyl (CBP) has been widely used as a host material for carrier transport and recombination host in organic light-emitting diodes (OLEDs) because of its excellent bipolar carrier transport ability, high thermal stability and comparatively high triplet energy level [7]. In this study, we developed new carbazole-based functional materials by structurally modifying CBP. 4,4'-Bis( $N$-carbazolyl)tolan (BCT), in which the central biphenyl unit of CBP is replaced by a 
diphenylacetylene (tolan) moiety (Scheme 1), was synthesized to clarify the influence of the acetylene spacer. 4,4'-Bis[N-(3,6-di-tert-butyl)carbazolyl]tolan (BCT-t-Bu) was also prepared. The synthesis and photophysical characteristics of BCT and BCT-t-Bu, together with their behavior in OLEDs as carrier transport and recombination host materials are reported.

\section{Experimental}

BCT was synthesized in $67 \%$ yield by Pd-catalyzed coupling of carbazole with 4,4'-dibromotolan [8]. A mixture of 4,4'-dibromotolan (336 mg, $1.0 \mathrm{mmol}$ ), carbazole (350 mg, 2.1 mmol), potassium carbonate $(830 \mathrm{mg}, 6.0 \mathrm{mmol})$, and palladium acetate $(22 \mathrm{mg}, 0.1 \mathrm{mmol})$ in toluene $(15 \mathrm{~mL})$ was refluxed under nitrogen for $24 \mathrm{~h}$. After the mixture was cooled to room temperature, the toluene was removed under reduced pressure. The residue was diluted with dichloromethane, washed with water, dried over $\mathrm{Na}_{2} \mathrm{SO}_{4}$, and purified by chromatography on silica gel (chloroform) followed by recrystallization from toluene to afford BCT (341 $\mathrm{mg}, 67 \%)$ as

colorless crystals: $\mathrm{Mp} 312{ }^{\circ} \mathrm{C} ;{ }^{1} \mathrm{H}$ NMR $\left(300 \mathrm{MHz}, \mathrm{CDCl}_{3}\right) \delta$ 7.29-7.35 (m, $\left.4 \mathrm{H}\right)$, 7.42-7.51 (m, 8 H), 7.62 (AA'BB', 4 H), 7.82 (AA'BB', 4 H), 8.18 (d, J = 7.7 Hz, 4 H); IR (KBr) 3049, 1602, 1518, 1450, $1226 \mathrm{~cm}^{-1}$; MS (MALDI-TOF) $\mathrm{m} / z, 508\left(\mathrm{M}^{+}\right)$. Anal. Calcd for $\mathrm{C}_{38} \mathrm{H}_{24} \mathrm{~N}_{2}: \mathrm{C}, 89.74 ; \mathrm{H}, 4.76$; , 5.51. Found: C, 89.74; H, 4.77; N, 5.35. BCT-t-Bu was synthesized in a $69 \%$ yield in the same manner by Pd-catalyzed coupling of 3,6-di-t-butylcarbazole [9] with 4,4'-dibromotolan. Unexpectedly, BCT-t-Bu was found to be quite insoluble in common organic solvents, and its low 
solubility hampered full spectroscopic characterization: MS (MALDI-TOF) $m / z 709\left(\mathbf{M}^{+}\right)$. Anal. Calcd. for $\mathrm{C}_{52} \mathrm{H}_{56} \mathrm{~N}_{2}$ : C, 88.48; H, 7.70; N, 3.82. Found: C, 88.39; H, 7.57; N, 3.69.

Single crystals of BCT suitable for analysis by X-ray diffraction were obtained by slow evaporation of a solution of BCT in toluene. All measurements were made on a Rigaku/MSC Mercury CCD diffractometer with graphite monochromated Mo-Ka radiation. A total of 5580 unique reflections $\left(2 \theta_{\max }=54.96^{\circ}\right)$ were collected, of which 3853 observed reflections were used in the structure solution (direct methods) and refinement (full-matrix least-squares) to give a final $R$ of 0.062. Crystal data for BCT: $\mathrm{C}_{38} \mathrm{H}_{24} \mathrm{~N}_{2}, M=508.59$, colorless plate, $0.40 \times 0.20 \times 0.05 \mathrm{~mm}$, monoclinic, space group $P 2_{1} / c$ (No. 14), $D_{\mathrm{c}}=1.317 \mathrm{~g} \mathrm{~cm}^{-3}, a=5.4070(7), b=34.756(5), c=$ 14.084(2) $\AA, \beta=97.2367(9)^{\circ}, V=2625.6(6) \AA^{3}, Z=4, T=123 \mathrm{~K}, \mu=0.76 \mathrm{~cm}^{-1}$.

Cyclic voltammetry was performed in benzonitrile $(\mathrm{PhCN})$ using $0.1 \mathrm{~mol} / \mathrm{dm}^{3}$ tetrabutylammonium perchlorate as the supporting electrolyte. Fluorescence and phosphorescence spectra were recorded of an EPA (diethyl ether/isopentane/ethanol $=5: 5: 2 \mathrm{v} / \mathrm{v}$ ) solution at a concentration of $10^{-5} \mathrm{~mol} / \mathrm{dm}^{3}$ at $77 \mathrm{~K}$ and of vacuum deposited films, which were prepared by thermal evaporation under high vacuum $\left(10^{-4} \mathrm{~Pa}\right)$, at $5 \mathrm{~K}$. Here note that the vacuum deposited films of BCT and BCT-t-Bu showed uniform films, indicating the formation of amorphous morphologies. PL quantum yields $\left(\Phi_{\mathrm{PL}}\right)$ were determined using an absolute PL quantum yield measurement system (C9920-02, Hamamatsu Photonics). Transient PL characteristics were determined using a streak camera system (C4334, Hamamatsu Photonics) with a nitrogen gas laser (excitation wavelength $=$ 
$337 \mathrm{~nm}$ ). To fabricate OLED devices, organic and metal layers were deposited by conventional thermal deposition on a clean glass substrate precoated with a $110 \mathrm{~nm}$-thick indium-tin-oxide (ITO) layer. Current density (I)-voltage $(V)$-luminance $(L)$ characteristics were measured using a semiconductor parameter analyzer (4155C, Agilent Technologies Inc.) connected to a silicon photodiode (1835-C, Newport Co.).

\section{Results and discussion}

\subsection{Photophysical characteristics}

Figure 1 shows the fluorescence and phosphorescence spectra of BCT and BCT-t-Bu, together with those of $\mathbf{C B P}$ as a reference compound. In EPA solution (०), BCT $\left(\lambda_{\mathrm{f}}=400 \mathrm{~nm}\right)$ exhibits red-shifted fluorescence compared with that of $\mathbf{C B P}\left(\lambda_{\mathrm{f}}=370 \mathrm{~nm}\right)$, consistent with its increased $\pi$-conjugation over CBP. BCT-t-Bu exhibits fluorescence at a similar wavelength to BCT, meaning introduction of four $t$-butyl groups onto the BCT skeleton has a negligible effect on the fluorescence spectrum in an EPA solution. Compared with CBP ( $\left.\lambda_{\text {phos }}=485 \mathrm{~nm}\right)$, the phosphorescence spectrum of BCT $\left(\lambda_{\text {phos }}=497 \mathrm{~nm}\right)$ also exhibits a slight red shift in EPA solution, while BCT-t-Bu $\left(\lambda_{\text {phos }}=460 \mathrm{~nm}\right)$ showed broad structureless emission at a shorter wavelength. In the deposited films ( $\bullet)$, the fluorescence maxima of $\mathbf{C B P}\left(\lambda_{\mathrm{f}}=404 \mathrm{~nm}\right), \mathbf{B C T}\left(\lambda_{\mathrm{f}}=440 \mathrm{~nm}\right)$ and BCT-t-Bu $\left(\lambda_{\mathrm{f}}=416 \mathrm{~nm}\right)$ are red-shifted by $34 \mathrm{~nm}, 40 \mathrm{~nm}$ and $17 \mathrm{~nm}$, respectively, compared with those in EPA solution (Table 1), because of the increased intermolecular interactions in the 
deposited films. The phosphorescence spectra of the deposited films are also red-shifted compared with those in solution; CBP (27 nm), BCT (131 nm) and BCT-t-Bu (52 nm).

The molecular interactions in the compounds can be also understood by comparing the fluorescence quantum yield $\left(\Phi_{\mathrm{f}}\right)$ in solution and solid films. Table 1 summarizes the $\Phi_{\mathrm{f}}$ values of CBP, BCT and BCT-t-Bu in solution and deposited films. Although $\Phi_{\mathrm{f}}$ is very high for BCT and BCT-t-Bu in solution, a pronounced decrease in $\Phi_{\mathrm{f}}$ was observed for both the solid films of BCT $\left(\Phi_{\mathrm{f}}=0.68\right)$ and BCT-t-Bu $\left(\Phi_{\mathrm{f}}=0.38\right)$. Although we expected a smaller decrease of $\Phi_{\mathrm{f}}$ in the solid film of BCT-t-Bu compared with that of BCT due to the presence of bulky t-butyl groups which hinder concentration quenching, quite opposite result was obtained, indicating the presence of unknown molecular interactions in these molecules.

Single crystal X-ray diffraction analysis of BCT revealed that the tolan moiety is almost planar in the solid state. The dihedral angle between the two benzene rings is $3.8^{\circ}$ while the carbazole units in BCT are twisted about the central tolan skeleton by $56.0^{\circ}$ and $59.5^{\circ}$ in the same direction (Fig. 2a). The crystal packing of BCT shows the characteristic herringbone structure caused by $\mathrm{C}-\mathrm{H} \cdots \pi$ interactions (Fig. $2 b$ ), and no significant $\pi$-stacking is observed in the crystal packing. Unfortunately, we have been unable to obtain single crystals of BCT-t-Bu suitable for study by X-ray diffraction.

Based on these results, the marked red shift of $131 \mathrm{~nm}$ observed for BCT can be attributed to specific intermolecular interactions of BCT in the solid film, presumably caused by its increased 
molecular planarity over that of CBP. Further, the inter-molecular interaction of $\mathrm{C}-\mathrm{H} \cdots \pi$ interaction in a BCT film would induce a large polarization of the triplet excited state, while the steric hindrance of the bulky $t$-butyl groups in BCT-t-Bu may prevent such intermolecular interactions, resulting in a smaller red shift.

Next, the compounds were used as hosts in host-guest films containing fluorescent and phosphorescent dopants. Highly fluorescent 1,4-dinitrile-2,5-bis(4-(bis(4-methoxyphenyl)amino) styryl)benzene (BSB-CN) was doped into BCT and BCT-t-Bu host layers to confirm their potential to act as host layers in OLEDs. As summarized in Table 2, at a doping concentration of 6 wt $\%$ BSB-CN, slightly higher values of $\Phi_{\mathrm{PL}}$ are obtained for BCT and BCT-t-Bu host layers compared with that obtained using CBP, suggesting that the tolan derivatives would be useful host materials for fluorescence-based OLEDs. Figure 3 shows the absorption and fluorescence spectra of BSB-CN in a toluene solution $\left(10^{-5} \mathrm{~mol} / \mathrm{l}\right)$. The spectral overlap between the absorption spectrum of BSB-CN and the fluorescence spectra of CBP, BCT and BCT-t-Bu films as shown in Fig. 1 is significant, ensuring the perfect energy transfer from the host layers into BSB-CN. We note that the fluorescence spectra of the all co-deposited films showed only BSB-CN emission. Thus, the small difference of $\Phi_{\mathrm{PL}}$ in the doped films would be due to the other factors such as dispersion condition of BSB-CN molecules in the host layers.

The tolan derivatives were also tested as host materials in phosphorescence-based OLEDs containing 6wt\% tris(2-phenylpyridinato)iridium (III) (Ir(ppy) $)_{3}$ as a phosphorescent emitter. 
Although $\Phi_{\mathrm{PL}}=90 \pm 3 \%$ for $\operatorname{Ir}(\mathrm{ppy})_{3}$ was obtained using a CBP host, a reduced value of $\Phi_{\mathrm{PL}}=66 \pm$ $3 \%$ was achieved with a BCT-t-Bu host layer and complete quenching of $\operatorname{Ir}(\mathrm{ppy})_{3}$ emission $\left(\Phi_{\mathrm{PL}}<\right.$ 1\%) was found with a BCT host layer. These results are consistent with the triplet energies estimated from the phosphorescence spectra of the compounds. In case of BCT-t-Bu, the double exponential decay curve of the $\operatorname{Ir}(\text { ppy })_{3}$ : BCT-t-Bu film with $\tau_{1}=0.55 \mu$ s and $\tau_{2}=1.75 \mu$ s also suggests imperfect energy confinement of the triplet excitons of $\operatorname{Ir}(\mathrm{ppy})_{3}$ because of the comparable triplet energies of the host layer and the guest molecule. Here, we note that although $\Phi_{\mathrm{PL}}$ is $66 \pm 3 \%$ at room temperature, it increased significantly to $90 \pm 3 \%$ at $5 \mathrm{~K}$. Thus, the energy levels of

BCT-t-Bu and $\operatorname{Ir}(\text { ppy })_{3}$ compete with each other. At low temperatures, the triplet excitons of $\operatorname{Ir}(\text { ppy })_{3}$ cannot overcome the potential barrier between $\operatorname{Ir}(\text { ppy })_{3}$ and BCT-t-Bu, leading to a very high $\Phi_{\mathrm{PL}}$. In addition, the red phosphor 2-(2-benzo[4,5-a]thienyl)pyridinato- $\left.\mathrm{N}, \mathrm{C}^{3}\right)$ iridium (acetylacetone) $\left(\mathrm{Btp}_{2} \operatorname{Ir}(\mathrm{acac})\right)$ was doped into the different host materials. Compared with $\Phi_{\mathrm{PL}}=40$ $\pm 3 \%$ with a CBP host, slightly lower $\Phi_{\mathrm{PL}}$ values of $29 \pm 3 \%$ and $24 \pm 3 \%$ were obtained using BCT and BCT-t-Bu as host layers indicating imperfect confinement of the triplet excitons of $\mathrm{Btp}_{2} \operatorname{Ir}(\mathrm{acac})$ or the presence of unwanted interactions between the host and guest molecules.

\subsection{OLED characteristics using the tolan derivatives as host materials}

The half-wave oxidation $\left(E_{1 / 2}{ }^{\text {ox }}\right)$ potentials of BCT and BCT-t-Bu in $\mathrm{PhCN}$ were determined to be $1.30 \mathrm{~V}$ and $1.22 \mathrm{~V}$ (vs. SCE), respectively. From the observed oxidation potential 
coupled with the absorption onset, the highest occupied molecular orbital (HOMO) and the lowest unoccupied molecular orbital (LUMO) levels of BCT were estimated to be $5.7 \mathrm{eV}$ and $2.4 \mathrm{eV}$, respectively. In a same manner, the HOMO and LUMO levels of BCT-t-Bu were estimated to be $5.6 \mathrm{eV}$ and $2.4 \mathrm{eV}$, respectively. Because these values are comparable to those of $\mathbf{C B P}$, the tolan derivatives BCT and BCT-t-Bu show potential to act as host materials in OLEDs.

To evaluate the ability of BCT and BCT-t-Bu to act as host materials in fluorescent OLEDs, we prepared devices with the structure ITO $(110 \mathrm{~nm}) / \alpha-\mathrm{NPD}(30 \mathrm{~nm}) / 6 \mathrm{wt} \% \mathrm{BSB}-\mathrm{CN}$ : host $(20 \mathrm{~nm}) / \mathrm{BCP}(20 \mathrm{~nm}) / \mathrm{Alq}_{3}(30 \mathrm{~nm}) / \mathrm{MgAg}(100 \mathrm{~nm}) / \mathrm{Ag}(10 \mathrm{~nm}) . \alpha-\mathrm{NPD}, \mathrm{Alq}_{3}$ and BCP are $N, N^{\prime}$-diphenyl- $N, N^{\prime}$-bis(1-naphthyl)-1,10-biphenyl-4,4'-diamine as a hole transport layer, tris(8hydroxyquinolinato)aluminum(III) as an emitter layer and 2,9-dimethyl-4,7-diphenyl-1,10phenanthroline as an electron transport layer, respectively. As shown in Fig. 3, the device containing CBP as a host showed a maximum external EL quantum efficiency $\left(\eta_{\text {ext }}\right)$ of $2.3 \%$ while the devices containing BCT and BCT-t-Bu host layers showed slightly higher $\eta_{\text {ext }}$ values of $3.0 \%$ and $2.6 \%$, respectively. Here, we note that a slightly lower drive voltage was required in the devices containing the tolan derivatives as the host material compared with that needed in the CBP device (Inset of Fig. 3). As suggested from the results of the photoluminescence study, probably the tighter molecular packing of BCT compared with that of CBP would lead to better carrier transport ability in the solid films.

Phosphorescence-based devices with the configuration ITO $(110 \mathrm{~nm}) /$ TPD $(50 \mathrm{~nm})$ / 
phosphor: host $(20 \mathrm{~nm}) / \mathrm{BCP}(10 \mathrm{~nm}) / \mathrm{Alq}_{3}(30 \mathrm{~nm}) / \operatorname{MgAg}(100 \mathrm{~nm}) / \mathrm{Ag}(10 \mathrm{~nm})$ were also examined. Here, TPD is $N, N^{\prime}$-bi(3-methylphenyl)- $N, N^{\prime}$-bis(phenyl)benzidine, which acts as a hole transport layer. With a BCT host layer $\eta_{\text {ext }}=4.5 \%$, while using a BCT- -Bu host layer gave $\eta_{\text {ext }}=2.0 \%$ when the dopant phosphor was $B t p_{2} \operatorname{Ir}(\mathrm{acac})$. In contrast, the $\mathbf{C B P}$ host layer gave a higher $\eta_{\text {ext }}$ of $7.0 \%$ for the same dopant. Furthermore, when the green phosphor $\operatorname{Ir}(\text { ppy })_{3}$ was used as the dopant, $\eta_{\text {ext }}$ decreased significantly to $0.1 \%$ using a BCT host layer and $3.8 \%$ using a BCT-t-Bu host layer(Fig. 4). This indicates that the tolan derivatives are not promising for use as host layers in phosphorescent devices.

\section{Conclusion}

The photoluminescence characteristics of CBP derivatives BCT and BCT-t-Bu were studied both in solution and in films. It was found that these materials are useful for host materials in fluorescence-based OLEDs, performing better than the traditional host material CBP. However, the low triplet energy levels of BCT and BCT-t-Bu in their films means they behave poorly as host materials in phosphorescence-based OLEDs.

\section{Acknowledgments}

This work was partially supported by a Grant-in-Aid for Scientific Research (C) (No.21550041) and a Grant-in-Aid for the Global COE Program, "Science for Future Molecular Systems" from the Ministry of Education, Culture, Sports, Science, and Technology, Japan. We 
thank Professor Tamotsu Inabe (Hokkaido University) for use of an X-ray structure diffractometer.

We are grateful to the Research Foundation for the Electrotechnology of Chubu and the Tatematsu Foundation for financial support. 


\section{References}

[1] M. Sigalov, A. Ben-Asuly, L. Shapiro, A. Ellern, V. Khodorkovsky, Tetrahedron Lett. 41 (2000), 8573.

[2] Y. Liu, M. Nishiura, Y. Wang, Z. Hou, J. Am. Chem. Soc. 128 (2006), 5592.

[3] J. Kido, K. Hongawa, K. Okuyama, K. Nagai, Appl. Phys. Lett. 63 (1993), 2627.

[4] H.-H. Chou and C.-H. Cheng, Adv. Mater. 22 (2010) 2468.

[5] Y. Zhang, L. Wang, T. Wada, H. Sasabe, Appl. Phys. Lett. 70 (1997), 2949.

[6] Y. Zhang, T. Wada, H. Sasabe, J. Mater. Chem. 8 (1998), 809.

[7] M. A. Baldo, S. Lamansky, P. E. Burrows, M. E. Thompson, S. R. Forrest, Appl. Phys. Lett. 75 (1999), 4.

[8] S. M. Waybright, K. McAlpine, M. Laskoski, M. D. Smith, U. H. F. Bunz, J. Am. Chem. Soc. 124 (2002), 8661.

[9] T. Xu, R. Lu, X. Liu, X. Zheng, X. Qiu, Y. Zhao, Org. Lett. 9 (2007), 797. 


\section{Figure captions}

Scheme 1: Molecular structures of CBP, BCT, BCT-t-Bu, BSB-CN, $\operatorname{Ir}(\mathrm{ppy})_{3}$, and $\mathrm{Btp}_{2} \operatorname{Ir}(\mathrm{acac})$.

Fig. 1: Fluorescence and phosphorescence spectra of CBP, BCT and BCT-t-Bu in an EPA solution $\left(10^{-5} \mathrm{~mol} / \mathrm{l}\right)(\circ)$ and deposited films $(\bullet)$.

Fig. 2: X-ray molecular structure (a) and crystal packing (b) of BCT.

Fig. 3: Fluorescence and phosphorescence spectra of BSB-CN in a toluene solution $\left(10^{-5} \mathrm{~mol} / \mathrm{l}\right)$.

Fig. 4: $J-\eta_{\text {ext }}$ characteristics of devices with the structure ITO (110 nm) / $\alpha-\mathrm{NPD}(30 \mathrm{~nm}) / 6 \mathrm{wt} \%$ BSB-CN: host $(20 \mathrm{~nm}) / \mathrm{BCP}(20 \mathrm{~nm}) / \mathrm{Alq}_{3}(30 \mathrm{~nm}) / \mathrm{MgAg}(100 \mathrm{~nm}) / \mathrm{Ag}(10 \mathrm{~nm})$ with a host layer of CBP (०), BCT ( $\square$ ) and BCT-t-Bu (A). The inset shows the corresponding $J-V$ characteristics of the OLEDs.

Fig. 5: J- $\eta_{\text {ext }}$ characteristics of devices with the structure ITO (110 nm) / TPD (50 nm) / EML (20 $\mathrm{nm}) / \mathrm{BCP}(10 \mathrm{~nm}) / \mathrm{Alq}_{3}(30 \mathrm{~nm}) / \operatorname{MgAg}(100 \mathrm{~nm}) / \mathrm{Ag}(10 \mathrm{~nm})$ devices with an EML of 6w\% $\operatorname{Ir}(\mathrm{ppy})_{3}: 1(\mathbf{\square}), 6 \mathrm{wt} \% \operatorname{Ir}(\mathrm{ppy})_{3}: 2(\mathbf{\Delta}), 6 \mathrm{wt} \% \mathrm{Btp}_{2} \operatorname{Ir}(\mathrm{acac}): \mathbf{B C T}(\square)$ and $6 \mathrm{wt} \% \mathrm{Btp}_{2} \operatorname{Ir}(\mathrm{acac}): \mathbf{B C T}-\boldsymbol{t}-\mathbf{B u}$ 
$(\Delta)$. 
Table 1: $\lambda_{\text {peak }}$, PL quantum efficiency of CBP, BCT and BCT-t-Bu in solution and vacuum deposited films

\begin{tabular}{|c|c|c|c|c|}
\hline \multirow[b]{2}{*}{ Material } & \multicolumn{2}{|c|}{ (in solution) } & \multicolumn{2}{|c|}{ (in solid films) } \\
\hline & $\lambda(\mathrm{nm})$ & $\Phi_{\mathrm{PL}}(\%)$ & $\lambda(\mathrm{nm})$ & $\Phi_{\mathrm{PL}}(\%)$ \\
\hline CBP & 370 & $80 \pm 3$ & 404 & $60 \pm 3$ \\
\hline $\mathrm{BCT}$ & 400 & $86 \pm 3$ & 440 & $70 \pm 3$ \\
\hline BCT- $t-\mathrm{Bu}$ & 399 & $97 \pm 3$ & 416 & $40 \pm 3$ \\
\hline
\end{tabular}


Table 2: $\lambda_{\text {peak }}$, PL quantum efficiency and transient life time of co-deposited films

\begin{tabular}{|c|c|c|c|c|}
\hline Guest material & Host material & $\lambda(\mathrm{nm})$ & $\Phi_{\mathrm{PL}}(\%)$ & $\tau(\mathrm{ns})$ \\
\hline \multirow{3}{*}{ BSB-CN } & $\mathrm{CBP}$ & \multirow{3}{*}{559} & $65 \pm 3$ & $1.5 \pm 0.3$ \\
\hline & BCT & & $71 \pm 3$ & $1.5 \pm 0.3$ \\
\hline & BCT-t-Bu & & $77 \pm 3$ & $1.5 \pm 0.3$ \\
\hline \multirow[t]{2}{*}{ Guest material } & Host material & $\lambda(\mathrm{nm})$ & $\Phi_{\mathrm{PL}}(\%)$ & $\tau(\mu s)$ \\
\hline & $\mathrm{CBP}$ & & $90 \pm 3$ & $1.0 \pm 0.3$ \\
\hline \multirow[t]{3}{*}{$\operatorname{Ir}(p p y)_{3}$} & BCT & 511 & $<1$ & - \\
\hline & BCT-t-Bu & & $66 \pm 3$ & $0.6,1.8 \pm 0.3$ \\
\hline & $\mathrm{CBP}$ & & $40 \pm 3$ & $5.4 \pm 0.3$ \\
\hline \multirow[t]{2}{*}{$\mathrm{Btp}_{2} \operatorname{Ir}(\mathrm{acac})$} & BCT & 617 & $29 \pm 3$ & $3.0,11.0 \pm 0.3$ \\
\hline & BCT-t-Bu & & $24 \pm 3$ & $5.5 \pm 0.3$ \\
\hline
\end{tabular}



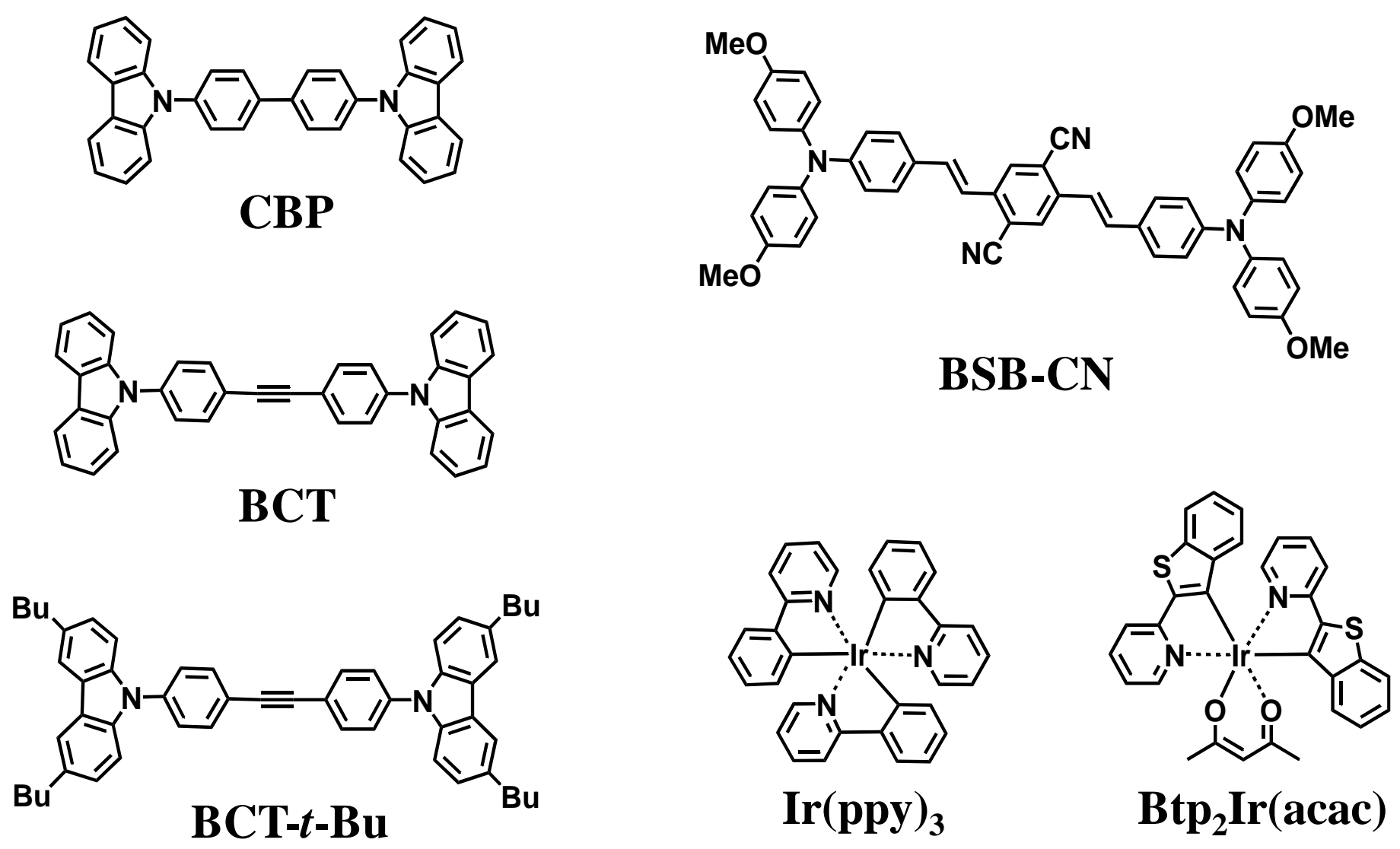

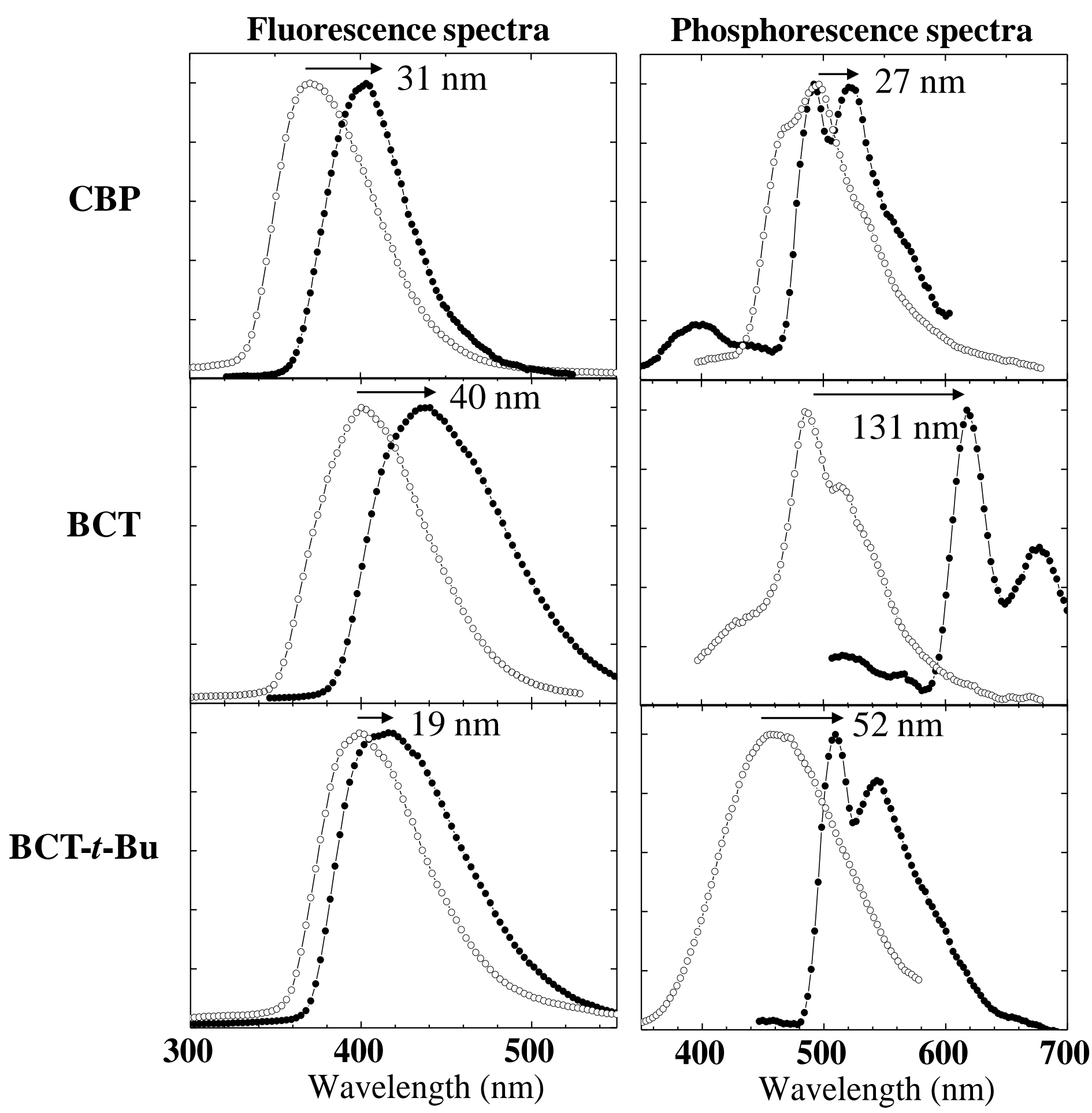

Figure 1 


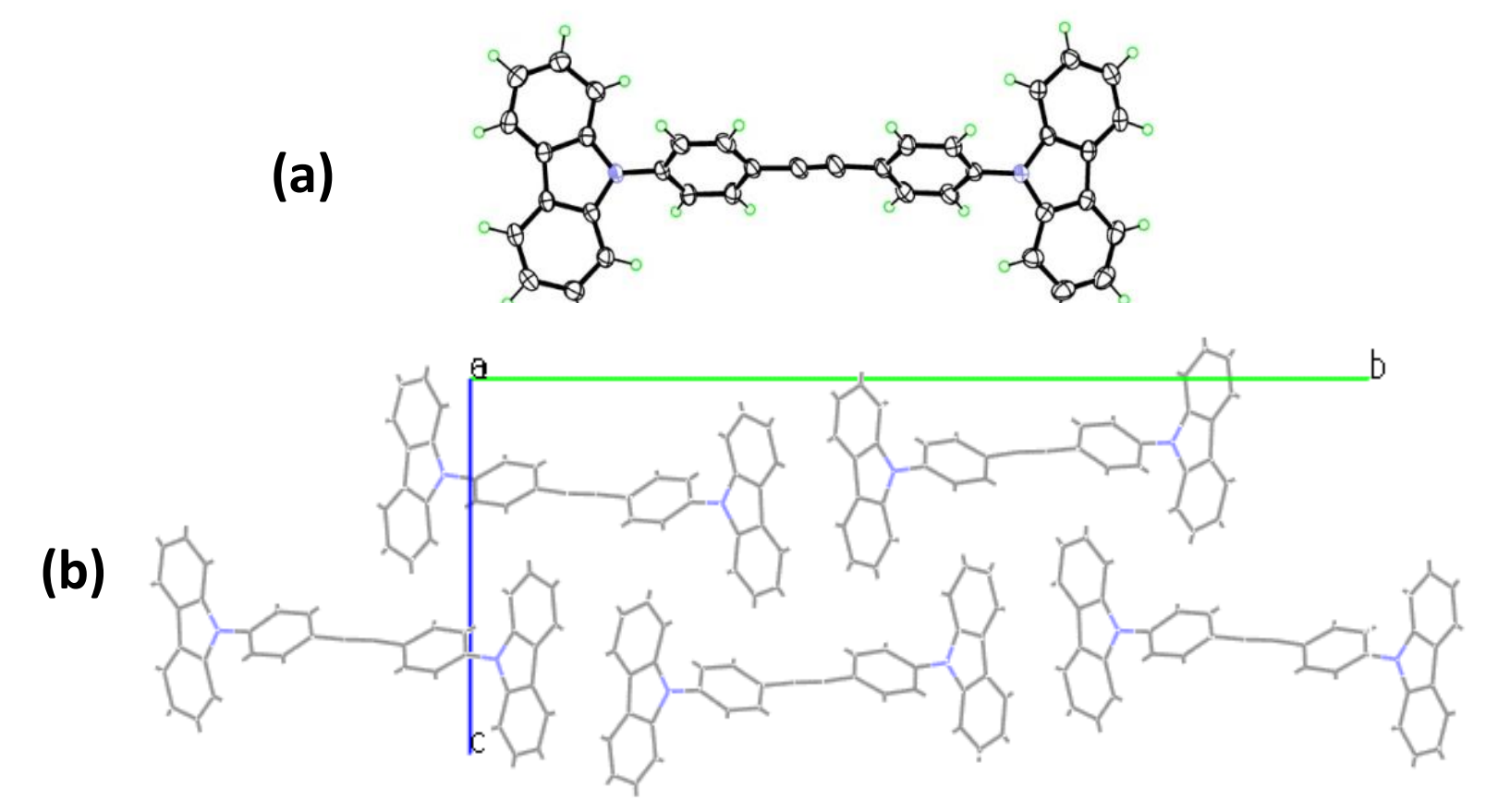

Figure 2 


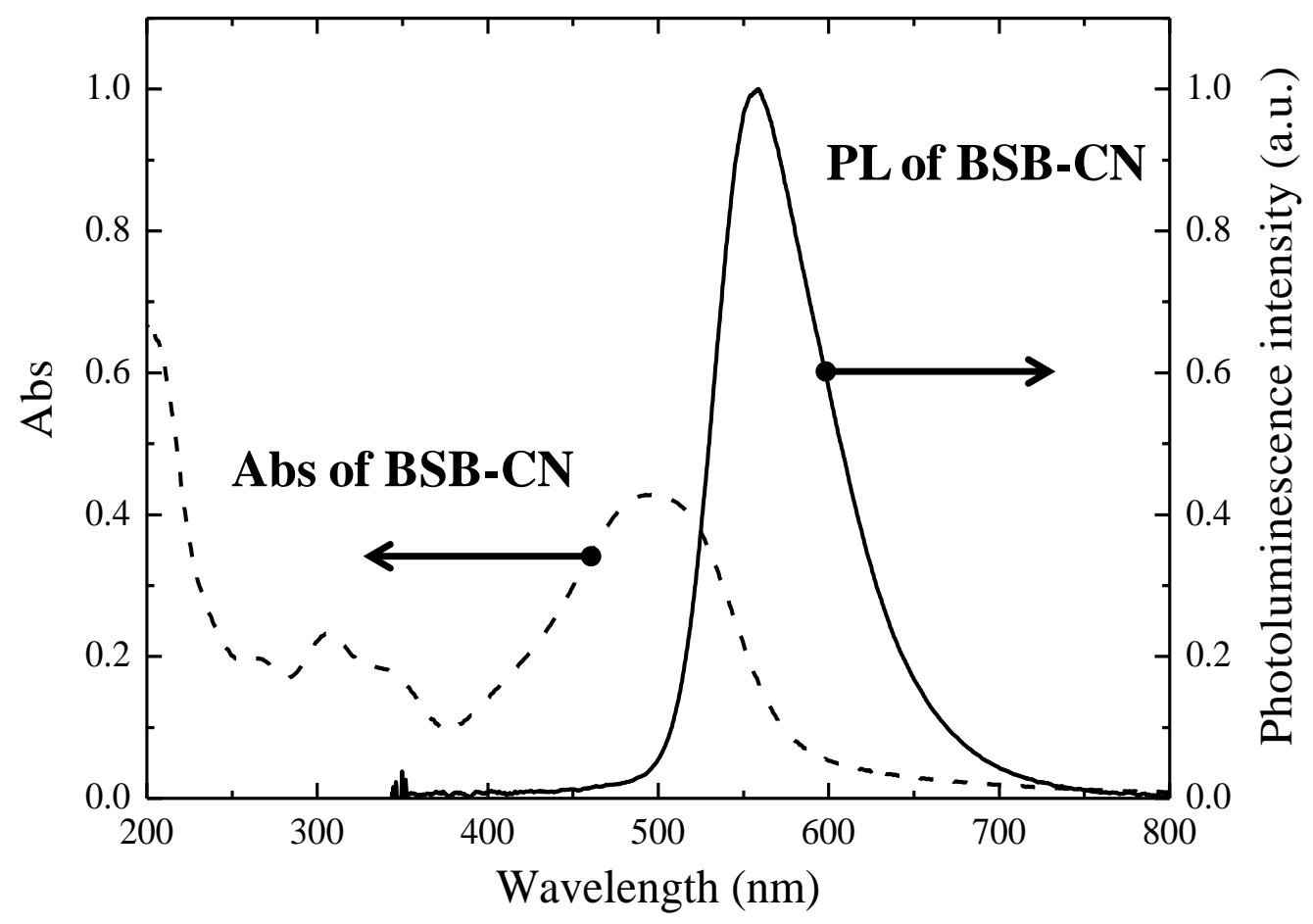

Figure 3 


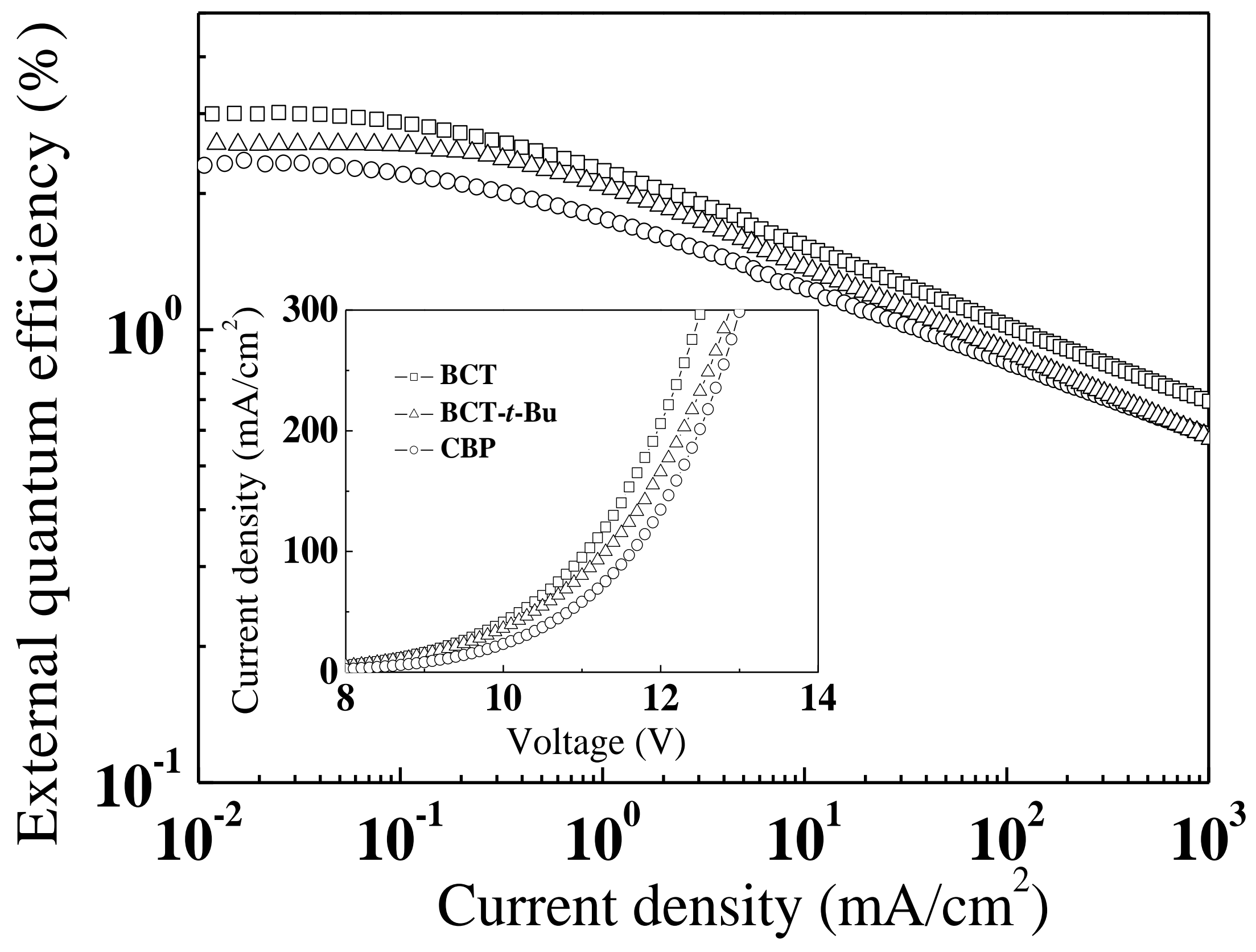

Figure 4 


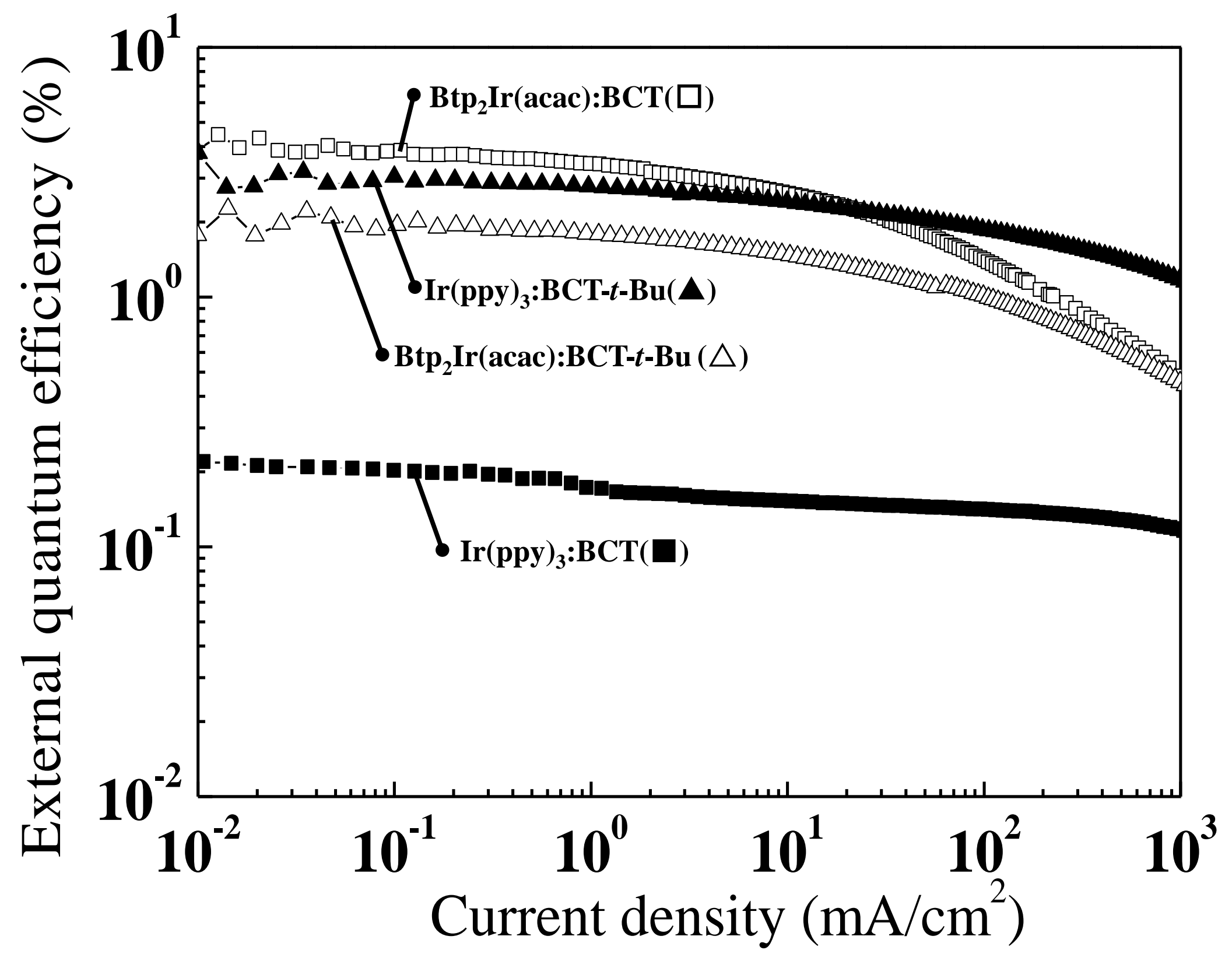

Figure 5 